\title{
Cardiac strangulation, a rare complication of epicardial pacemaker leads during growth
}

\author{
B Eyskens, L Mertens, P Moerman, H Ector, W Daenen, M Gewillig
}

UZ Leuven, B 3000 Leuven, Belgium: Department of Congenital Cardiology B Eyskens

L Mertens

M Gewillig

Department of

Cardiac surgery

W Daenen

Department of

Cardiology

H Ector

Department of

Pathology

P Moerman

Correspondence to:

Marc Gewillig MD,

Department of Congenita Cardiology, UZ Leuven, B 3000 Leuven, Belgium. Accepted for publication 4 November 1996
Figure 1 The anteroposterior (left) and the lateral chest $x$ ray (right) show the two recently implanted epicardial steroid leads on the anterior surface of the heart. The old epicardial lead encircles the anterior surface of the heart; at necropsy this lead was found to have strangulated the apex.

\begin{abstract}
A six year old boy with an epicardial pacing lead since infancy presented with thoracic pain triggered by movement. The pain was thought to be musculoskeletal, but two weeks later he collapsed and died in ventricular fibrillation. Necropsy showed strangulation of the ventricular apex by the epicardial lead.
\end{abstract}

(Heart 1997;77:288-289)

Keywords: pacing in infants; epicardial lead; strangulation; coronary spasm

\section{Case report}

Surgical closure of a ventricular septal defect in an eight month old boy with atrioventricular and ventriculoarterial discordance was complicated by total atrioventricular block. A permanent epicardial pacemaker lead (Medtronic $5815 \mathrm{~A}$ ) was implanted on the anterior surface of the morphologically right sided left ventricle and connected to a generator in the anterior

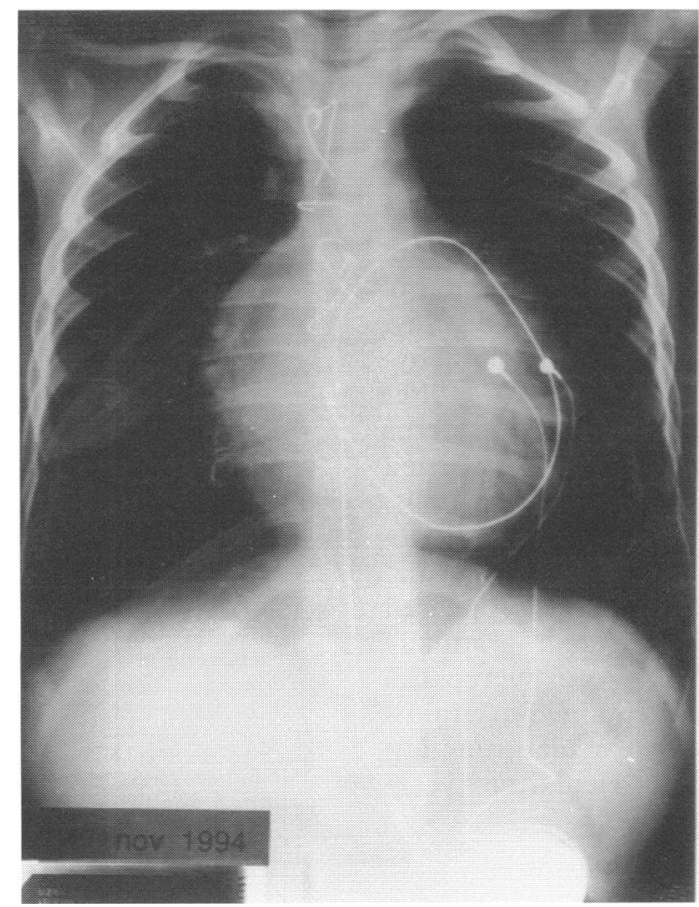

abdominal wall. A large loop of lead was left to allow for growth. The generator was removed $\vec{\omega}$ two years later because of a lead insulation defect and an endocavitary system was placed, but this failed and was replaced after two years by a new epicardial system.

At the age of six the boy complained of $\stackrel{\infty}{\infty}^{\circ}$ episodes of severe chest pain, each lasting for 을 about 10 minutes, and induced by brisk move- $]$ ments. Pacemaker function was normal. A 3 chest radiograph showed the two recently introduced leads as well as the original, dis- $\triangle$ connected epicardial lead (fig 1 ). The pain was $\vec{\varphi}$ thought to be a local musculoskeletal problem $\stackrel{\bullet}{v}$ and it improved after an abdominal bandage 0 was prescribed to prevent the generator pushing against the lower ribs.

Two weeks later he complained of intense abdominal discomfort and collapsed while $\mathbb{D}$ playing. He remained conscious for about two minutes but then became pulseless. On arrival 응 of the medical team the ECG showed ventricular fibrillation with pacemaker spikes. Attempted resuscitation resulted in QRS complexes but without pump function.

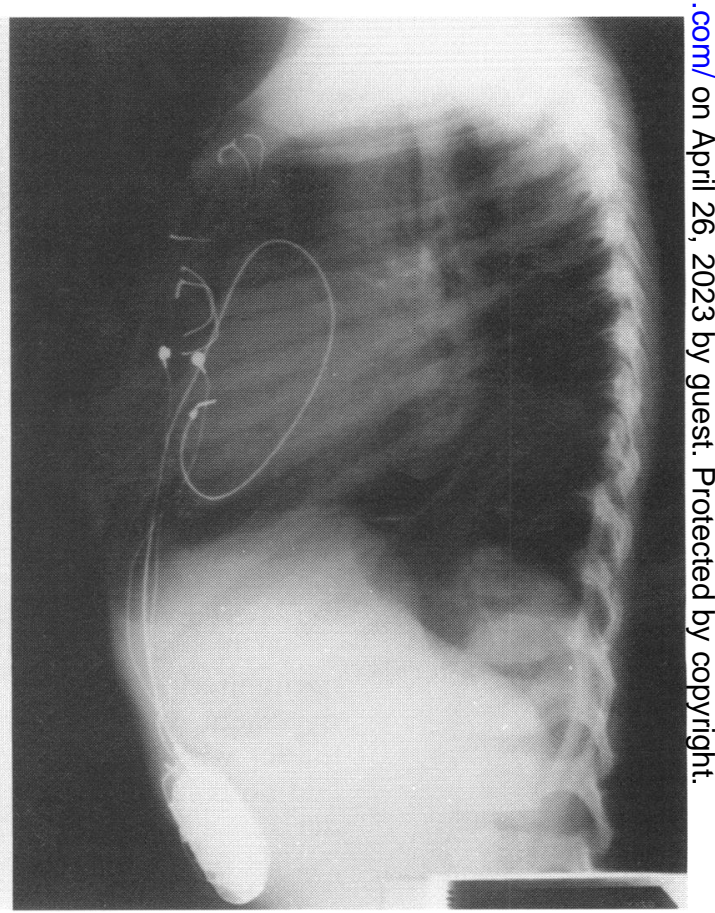


Figure 2 Posterior view of the heart (left) and detail of the apex (right) showing epimyocardial compression and strangulation by the pacing lead.

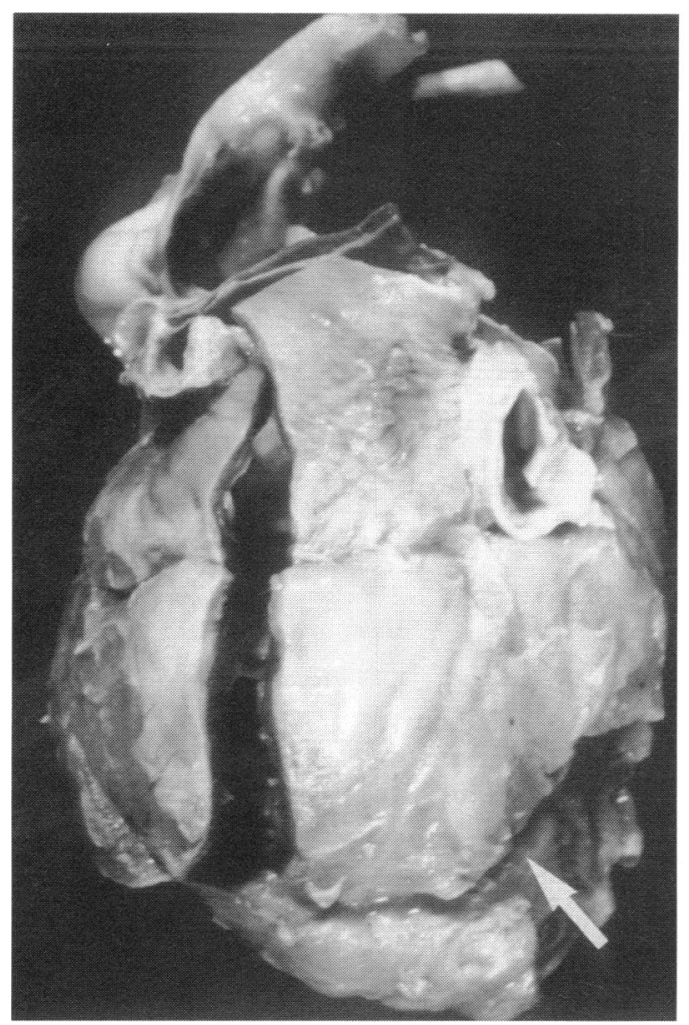

Necropsy showed that the original lead had made a large loop on the anterior surface of the heart and had carved a deep groove at the posterior aspect of the apex, causing epimyocardial compression with deformation of the left ventricular cavity (fig 2 ).

\section{Discussion}

We hypothesise that the fatal event in this child was myocardial ischaemia causing ventricular arrhythmias. Recurrent chest pain had been interpreted as musculoskeletal pain, but in retrospect it was probably angina.

Progressive entrapment of the myocardium by a pacing lead during growth is very rare. Compression of the right ventricular outflow tract (RVOT), the coronary arteries, or the ventricular wall may occur. Symptoms of car-

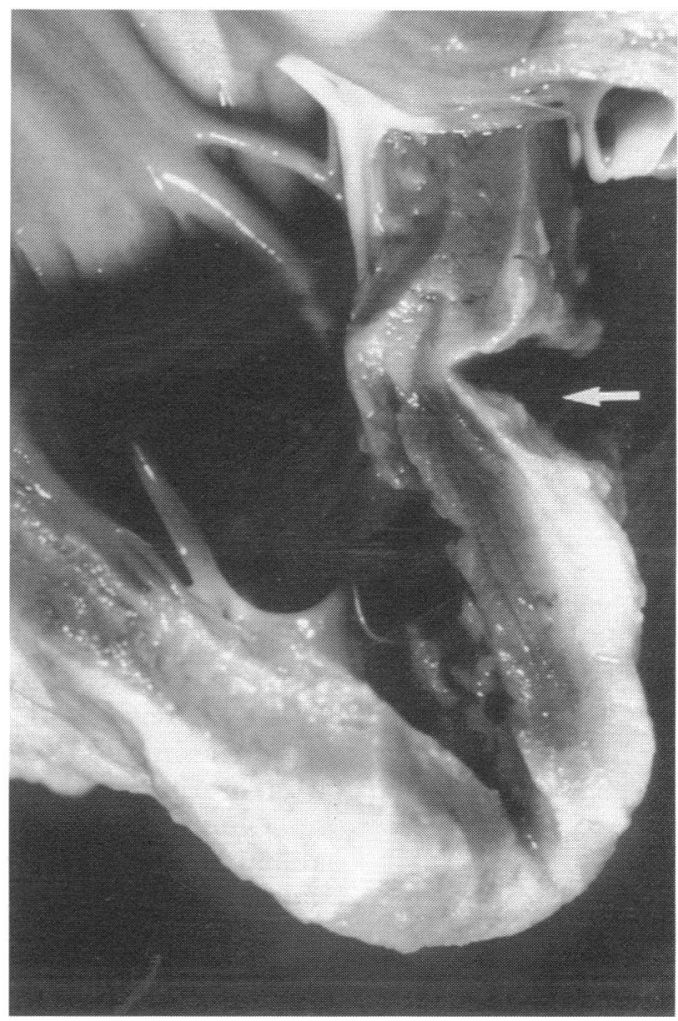

diac strangulation may be a new murmur, impaired exercise tolerance, right ventricular failure, syncope due to severe RVOT obstruction, or chest pain. ${ }^{1-3}$ This pain is not exercise related but induced by sudden movements causing traction on the lead, with coronary compression or spasm and intermittent myocardial ischaemia. In suspected cases a ventriculogram and coronary angiogram confirms the diagnosis. Surgical removal of the lead is lifesaving.

1 Brenner J I, Gaines S, Cordier J. Cardiac strangulation: two-dimensional echo recognition of a rare complication of epicardial pacemaker therapy. Am 7 Cardiol 1988; 61:654-6.

2 Perry JC, Nihill MR, Ludomirsky A. The pulmonary artery lasso: epicardial pacing lead causing right ventricular outflow obstruction. PACE 1991;14:1018-23.

3 Sugita T, Yokota Y, Ando F. Cardiac strangulation with permanent epicardial pacemaker lead. Kyoba Geka 1992 45:456-8. 